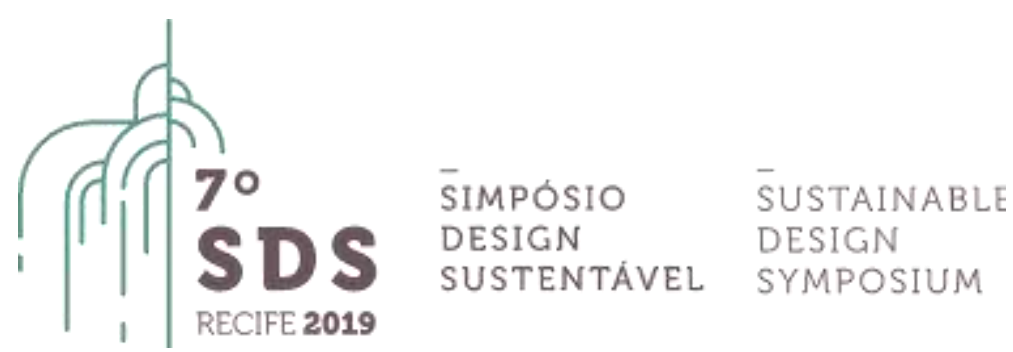

\title{
Sementes em correspondência e os aspectos da sustentabilidade na comunidade do Maracanã, São Luís - MA
}

\author{
Tayomara Santos dos Santos ${ }^{1}$, Raquel Gomes Noronha ${ }^{2}$ e Gisele Reis Correa Saraiva ${ }^{3}$ \\ ${ }^{1}$ Universidade Federal do Maranhão - UFMA, DEDET, tayomara.ssantos@gmail.com \\ ${ }^{2}$ Universidade Federal do Maranhão - UFMA, DEDET, raquelnoronha79@gmail.com \\ ${ }^{3}$ Universidade Federal do Maranhão - UFMA, DEDET, gisarco41@gmail.com
}

\begin{abstract}
Resumo: Este artigo trata de aspectos da produção artesanal com o uso de sementes ornamentais encontradas na Área de Proteção Ambiental - APA - do Maracanã desenvolvidas na comunidade, por meio do codesign e das relações existentes entre designers e artesãs com os materiais e o ambiente no qual estão inseridos, por meio das práticas de correspondência, $e$ as reflexões do antropólogo britânico Tim Ingold. A escolha do Maracanã, bairro de São Luís (MA), como território se deve ao grande contingente de sementes florestais nativas e propicias à atividade artesanal e também por ser uma comunidade de grande repertório cultural que expressa um significativo valor identitário capaz de fomentar o desenvolvimento de fatores importantes com social, econômico e ambiental, inerentes à construção de práticas sustentáveis.
\end{abstract}

Palavras-chave: Design Anthropology, Sementes, Saberes Tradicionais, Correspondências, Sustentabilidade.

\section{Introdução}

O Maranhão é um estado brasileiro que embora esteja geograficamente localizado na região nordeste, o seu território encontra-se numa área de transição com a região norte. Esse fato singular contribui para que o estado apresente um variado ecossistema rico em biomas, que vai da Floresta Amazônica e litoral a cerrados e pântanos. Essa variedade na fauna e flora propicia grande diversidade de matérias primas que o faz um grande produtor de artesanato. De acordo o Programa de Artesanato Brasileiro - PAB (2007), no Maranhão, o artesanato é uma fonte exclusiva de renda para cerca de 50.000 pessoas, que transformam as fibras de buriti (Mauritia flexuosa) em Barreirinhas, bananeira (Musa spp.) em São Luís Gonzaga, o babaçu (Attalea speciosa) na Baixada Maranhense, a cerâmica nos municípios de Alcântara, Rosário e São José de Ribamar, entre outros materiais, nos mais variados produtos artesanais, incluindo tal população em um sistema que coloca em correspondência os valores tradicionais com os valores materiais e econômicos envolvidos nestas produções.

A região amazônica é, no Brasil, o grande produtor de artefatos artesanais produzidos a partir das sementes. Toneladas de sementes são coletadas durante todo ano e vários setores da sociedade estão envolvidos nos aspectos econômicos, sociais e ambientais da produção. A RSA Rede Sementes da Amazônia - é um grupo de pessoas e instituições, lideradas pela Universidade 
Federal da Amazônia, que trabalha com o objetivo de realizar e consolidar o setor de sementes na região amazônica, realizando cursos de manejos de sementes para artesanato com o objetivo de identificar, coletar, beneficiar, acondicionar e armazenar, capacitando as pessoas para este tipo de trabalho. Estados como Pará, Acre, Amazonas, Amapá, Rondônia, Roraima e Tocantins compõem o grupo (REDE DE SEMENTES DA AMAZÔNIA, 2007). O Maranhão, embora integre esse cenário territorial, não está inserido nesse grupo, carecendo ainda de investimentos direcionados à investigação de suas potencialidades territoriais e nativas principalmente no que tange a atividade com sementes ornamentais.

Sobre o uso de sementes na produção artesanal entre os anos 2008/2010 foi verificada grande a quantidade de sementes de juçara ${ }^{1}$ (Euterpe Oleácea Mart) desperdiçadas diariamente no bairro do Maracanã, em São Luís do Maranhão, após o despolpamento do fruto (CORREA, 2010). Este bairro é considerado um dos maiores produtores do vinho ${ }^{2}$ da juçara na região metropolitana da capital maranhense. Recentemente, a partir de iniciativa extensionista ${ }^{3}$, a atividade artesanal desenvolvida foi direcionada ao beneficiamento e uso das sementes de juçara e atualmente estendendo-se ao uso de outras espécies nativas através do trabalho conjunto entre designers e artesãs.

Os resultados aqui apresentados são frutos de um processo de correspondência, prática de construção coletiva de conhecimento que busca um certo design por meio da empatia e da atencionalidade, seguindo as reflexões de Tim Ingold, antropólogo britânico que trouxe ao seu campo de atuação a possibilidade de ser o design o meio pelo qual a antropologia tornar-se-á uma prática de intervenção e diálogo cultural. Quando propomos tal prática no campo do design, estamos potencializando a inclusão no diálogo das próprias sementes, do meio ambiente, dos seres vivos que estão em correspondência nesta cadeia produtiva, que transcendem os valores financeiros e funcionais envolvidos. O estudo parte da abordagem teórica e metodológica do design anthropology tomando como base o pensamento de Ingold, sobre práticas de correspondências e, neste contexto, no saber-fazer tradicional na produção de artefatos com o uso das sementes ornamentais.

Tais práticas de correspondência envolvem a observação participante e a produção coletiva de 'coisas', para que saiamos de um discurso sobre a materialidade e que possamos, assim, trazer os materiais e o ambiente de volta à vida, desencerrando-os de ciclos de consumo e proporcionando que outros valores emerjam destas práticas, como Ingold (2012) propõe. O autor argumenta sobre a estabilidade daquilo que denominamos por objetos e propõe que os tomemos como 'coisas', no sentido em que a sua constituição extrapola os limites da materialidade, como seres em processo de correspondência entre seus materiais de constituição e o próprio ambiente.

O manejo das sementes na cadeia produtiva do artesanato foi a porta de entrada para que chegássemos a tais práticas. A correspondência é uma forma de se posicionar no mundo e estar em relação aos outros e consolida o trabalho conjunto realizado na comunidade em prol da valorização das manifestações materiais e simbólicas da cultura local e de sustentabilidade.

\section{Maracanã: território, identidade e artesanato}

O Maracanã, considerado um bairro rural da grande ilha de São Luís, localizado nas proximidades do Distrito Industrial, é reconhecido pela sua forte representatividade em tradições

\footnotetext{
1 Juçara é nome pelo qual o açaí é conhecido no estado do Maranhão.

${ }^{2}$ Como o maranhense chama o suco produzido do fruto.

${ }^{3}$ Projeto de Extensão "Artesanato no Maracanã: utilização da semente de juçara na produção artesanal”, promovido pelo Núcleo de Pesquisa em Inovação Design e Antropologia - NIDA, do Departamento de Desenho e Tecnologia DEDET/ Curso de Design da Universidade Federal do Maranhão - UFMA.
} 
e identidade cultural a exemplo de manifestações folclóricas como o Bumba-meu-boi do sotaque de matraca ${ }^{4}$ que carrega o nome do bairro, o Boi do Maracanã carinhosamente chamado pela população ludovicense como "Batalhão Pesado", assim como pela valorização de sua história através de festividades religiosas e culturais como o culto ao Divino Espírito Santo e a tradicional Festa da Juçara, cuja ocorre desde a década de 70, devido o bairro ser um grande produtor do fruto da juçara. A festa da juçara é vista como o maior símbolo cultural da comunidade e promove o envolvimento dos moradores, valoriza a mão-de-obra local, gera empregos temporários.

Durante uma conversa informal na comunidade, a moradora e artesã Tatiane Santos conta que quando os primeiros habitantes chegaram ao local, encontraram uma quantidade expressiva de pássaros, conhecidos pelos nativos como Maracanã, por trata-se de uma área de floresta vasta, rica em alimentos para eles, assim passaram a chamar o até então povoado recém-formado. Nesse sentido, Krucken, (2009, p.18), nos orienta que "para dinamizar os recursos do território e valorizar seu patrimônio cultural, é fundamental reconhecer e tornar reconhecíveis valores e qualidades locais, esta é a principal função do design nesse campo" e ressalta que outra função importante do design a considerar é "saber dimensionar o aspecto ambiental na cultura e na prática projetual com o intuito de reduzir o impacto ambiental de materiais e processos". Seguindo essa linha, Vezzoli et al (2018, p. 18) nos aponta outro aspecto importante a dimensionar, o aspecto econômico da sustentabilidade e como deve atuar o design sob essa ótica, para os autores, "um designer orientado pela perspectiva ortodoxa de crescimento, busca aumentar a produção, enquanto um designer pautado pelo conceito de sustentabilidade tem como foco em soluções qualitativas do bem estar". Para tanto, é fundamental considerar que os benefícios de tais práticas sustentáveis demandam tempo para tornarem-se visíveis a população, no entanto, promovem melhorias de vida material, nas condições de saúde, na longevidade, no exercício da cidadania, no aperfeiçoamento pessoal e do trabalho coletivo, nas ações de preservação e conservação do ambiente (VEZZOLI et al, 2018). Com os recursos naturais disponíveis no entorno, as mulheres do Maracanã desenvolvem uma série de peças artesanais como arranjos florais da fibra do anajá (Scheelea Amylacea) e a fibra da juçara (Euterpe oleracea mart) vendidas principalmente na Festa da Juçara todo mês de outubro.

O escritor e poeta maranhense Ivan Sarney (2011), nos conta que, a agrônoma e moradora do Maracanã, Rosa Martins Mochel, inspirada na natureza da região, em seus encantos sazonais e verdes e em nossas tradições alimentares idealizou a Festa da Juçara, criada pelo dinamismo, pelo amor, pela devoção ao meio ambiente e à cultura local, quando residia no bairro, num belo e frondoso sítio, onde produzia mudas e cultivava plantas ornamentais e frutíferas. Na comunidade ela criou um projeto de educação infantil, denominado Casa de Alice para educar e promover o lazer das crianças do bairro, com inspirações nitidamente ambientais. Rosa Mochel deixou plantadas as sementes dessa festa, transformada numa tradição popular, pela determinação, pela garra dos moradores que organizam os festejos. Correa (2010) afirma que foi Rosa Mochel quem incentivou o surgimento das práticas artesanais no Maracanã, orientando as mulheres da comunidade que se ocupavam somente dos afazeres domésticos cotidianos e que não tinham renda, a transformar em peças artesanais o caule das árvores derrubadas por conta da retirada das pedras, pois antes do uso para o artesanato, essas árvores eram transformadas em carvão. Cardoso (2008, p. 245) por sua vez afirma que o artesanato utiliza recursos naturais na produção de objetos e o designer, além de projetar, sobrepõe a qualidade de vida como prioridade, projetando-o de forma consciente, a qual vem exercendo de forma discreta, porém ativa ao longo do processo de surgimento e ressurgimento das questões ambientais.

Nesse sentido, após alguns anos do surgimento do artesanato, as mulheres continuam trabalhando com o caule das árvores chamado de 'mondrongos', no entanto, recentemente, foi

\footnotetext{
${ }^{4}$ Existem cinco sotaques (Matraca, Zabumba, Da baixada, Costa-de-Mãos e Orquestra) dos grupos de bumba-meu-boi do Maranhão.
} 
agregada ao trabalho artesanal a confeç̧ão de biojoias com o uso de sementes ornamentais, inicialmente com a semente de juçara, devido a sua maior disponibilidade nos quintais e sítios onde são descartadas após o despolpamento do fruto. Esse trabalho constituiu-se a partir de pesquisas e por ação extensionista com professores, alunos da graduação e pós-graduação em design, cujo objeto de pesquisa é o trabalho artesanal em torno das sementes ornamentais encontradas na Área de Proteção Ambiental. Esta parceria rendeu a criação de um grupo de mulheres artesãs determinadas e inspiradas ao trabalho com sementes, o grupo Fruta Rara.

O trabalho em torno das sementes ornamentais será abordado no decorrer desta narrativa, pois antes se faz necessário o entendimento sobre a abordagem de design anthropology em práticas projetuais que envolvem o codesign em comunidades, como o Maracanã. A correspondência já vem sendo discutida no campo do design e nos cabe aqui contextualizar seu escopo teórico para explicitarmos como tais relações acontecem na imersão no campo.

\section{Um caminho de correspondências}

\subsection{Design Anthropology (DA)}

Há quase cinquenta anos o diálogo entre o design e a antropologia iniciou-se e desenvolveu-se de inúmeras formas: inicialmente para embasar estudos antropométricos na ergonomia (SANDERS, 2002); direcionou-se para a reflexão sobre a própria prática do design, indicando uma virada humanística, em detrimento do paradigma funcionalista, como se observa no clássico livro Design for the real world, de Papanek (1973). Neste percurso, designers e antropólogos assumiram o papel de pesquisadores na produção de bens em que o foco eram as necessidades do usuário, e este era observado etnograficamente, para ter suas ações, formas de ver e pensar com o artefato em questão, mapeadas e analisadas.

Mais recentemente, para além de uma abordagem etnográfica, o design e a antropologia aliam-se de forma a produzir uma terceira via de conhecimento, na qual nem o design se vale de aspectos metodológicos da antropologia - fórmula desgastada ao longo das três últimas décadas, em que para se projetar, valia-se das práticas etnográfica advindas da teoria antropológica - e nem uma antropologia do design, na qual a antropologia se vale do design como objeto de estudo.

Para Gunn et al (2013), o DA tem amadurecido como uma subdisciplina desenvolvendo seus próprios conceitos, métodos, práticas de pesquisa e profissionais, seu próprio repertório que congregam na produção de conhecimento. Halse (2013) dialoga afirmando que o DA permite pensar o design de forma democrática em um exercício que permite extrapolar possíveis futuros tanto para designers quanto para os detentores de conhecimentos tácitos, como entendemos as artesãs da comunidade do Maracanã. $O$ autor ainda afirma que essa relação forma novos cenários criativos desafiadores e possibilita explorar imaginações particulares onde todos os que participam são protagonistas, aludindo à sua própria herança epistemológica ${ }^{5}$ advinda das reflexões do design participativo escandinavo, que na década de 1970 embasou as discussões nos sindicatos sobre a chegada das máquinas e a consequente substituição do trabalho humano.

Congregando abordagens metodológicas no processo de trabalho colaborativo de ambos os campos (design e antropologia), o DA tem suas especificidades e pontos de interesse e seu maior desafio é desenvolver ferramentas e práticas de colaboração em comum, principalmente no que tange ao que seria a maneira mais assertiva de se observar de modo participante. A antropologia, por sua vez, tem se dedicado a uma longa história de estar em contato com culturas diversas e encerra-las em um processo descritivo, resultando em teses e laudos, que pouco têm

\footnotetext{
${ }^{5}$ As discussões de Halse (2010; 2013), Pelle Ehn (2015), Thomas Binder (2011), Eva Brandt (2008) também são fundamentais para entendermos a construção democrática dos países escandinavos e, neste contexto, a construção de metodologias projetuais de design que visam à este fim, a dissolução de hierarquias do processo projetual.
} 
ressonância na vida dos sujeitos de tais pesquisas. O percurso da antropologia pós-moderna, a partir da década de 1980 foi trazer à baila os dilemas da escrita etnográfica, do relativismo cultural, da simetria nos processos de análise, da diversidade cultural, e todo este esforço empreendido culmina na crítica da própria etnografia, à qual Ingold (2016) dedica-se, convocando que a antropologia seja mais engajada e ativa nos contextos em que se dão as pesquisas. Assim, 0 DA traz essa prerrogativa de ativar a antropologia por meio do design, desvencilhando-se das armadilhas da representação, assunto ao qual refletimos teoricamente em outro momento (NORONHA, 2018).

\subsection{Correspondência como prática de estar com o outro}

Ingold (2016, p.406) destaca que no trabalho de campo, o pesquisador diz às pessoas que está lá para aprender com elas. Ele passa a ter expectativa de que elas lhe ensinem algo sobre suas habilidades práticas, ou que elas lhe expliquem o que pensam sobre as coisas. Logo, o pesquisador se esforça para lembrar-se do que observou, o que as pessoas lhe disseram e, para garantir, tendem a registrar tudo em anotações deixando de vivenciar o campo de fato. Ingold entende esse propósito como se o pesquisado fosse secretamente o 'informante' do pesquisador, logo, isso converte sua experiência e sua memória em notas, material e/ou meros dados científicos nos quais o pesquisador espera poder se apoiar posteriormente durante o projeto de oferecer uma descrição. No âmbito da pesquisa isto não é o problema, mas "a distorção temporal que faz com que o resultado dos encontros com as pessoas pareça como sua condição prévia" (JOHANNES apud INGOLD, 2016, p.406). Para Hockey e Forsey (2012), o campo nunca é vivido como tal quando o pesquisador está inserido de fato lá, ocupando-se dos afazeres da vida quotidiana do outro no ambiente, na maioria das vezes ele só emerge quando o deixa e começa a escrever sobre o campo, pois antes o pesquisador está simplesmente realizando um trabalho de campo etnográfico, pois este método, de fato, resulta em uma representação.

Quando a designer se vê na incumbência de 'projetar' para situações mais específicas, na qual se convergem muitos pontos de vista, cosmovisões ou mesmo ações e realizações de design que não sejam necessariamente chegar a um artefato, se depara com métodos que talvez não sejam os mais adequados aos seus objetivos. Neste contexto, retomando ao ambiente pesquisado neste artigo - a comunidade do Maracanã - surge a reflexão de que o trabalho realizado a partir de uma simples pesquisa de campo tomou outro sentido. Entendemos que a pesquisa, na verdade, se dava a partir de práticas de correspondências que vão além do trabalho de campo etnográfico por meio da observação participante.

Figura 01 - Diferença entre Interação e Correspondência

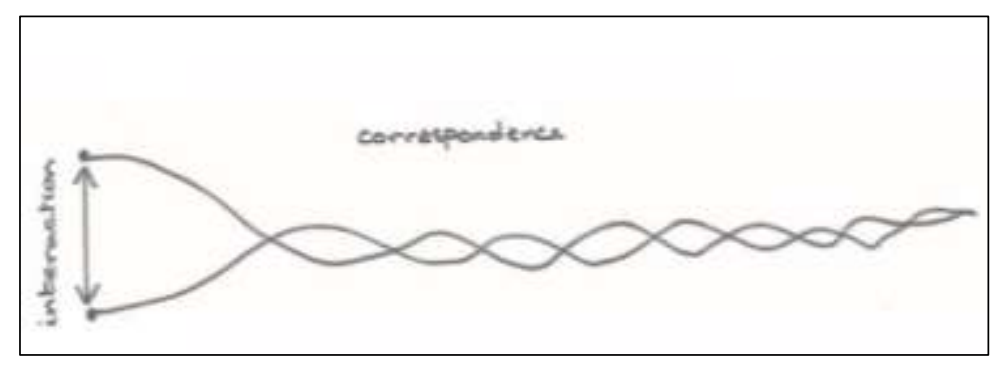

Fonte: Ingold, 2013.

Para Ingold, a implicação do prefixo inter-, em 'interação', é que as partes do que interagem são fechadas umas às outras (Figura 02), como se elas pudessem ser conectadas apenas através de algum tipo de operação de ponte como indo do ponto $A$ ao ponto $B$, logo, esse contato pode ser apenas racional sem levar em consideração os sentidos. Na correspondência, por outro lado, percebe-se movimento entre vários pontos, ou seja, linhas que se envolvem como uma 
"melodia em contraponto", nas palavras do autor, essas linhas em movimento são "relações de reciprocidade e harmonia entre todas as coisas naturais (as pessoas, a natureza) e espirituais (energias, crenças, dogmas), terrestres (o que está ao nosso alcance) e celestes (cosmos), essas relações se dão pela atenção que damos nas realizações com o outro." (INGOLD, 2013, p.107).

O autor nos mostra ainda que ao buscarmos maneiras de responder ao mundo, em vez de descrevê-lo ou representá-lo com os resultados oriundos da pesquisa etnográfica, devemos responder a ele, por meio das trocas com as pessoas, com o ambiente também com aquilo que não vemos (místicas, crenças, dogmas que circundam as comunidades tradicionais), mas sentimos e sabemos que está lá presente influenciando no cotidiano do outro. Desta forma, se obtém o um profundo entendimento sobre o que é buscado, independente de para qual fim essa ação se destina, se para a produção de uma 'coisa', processo ou conhecimento.

A base do conhecimento se encontra especificamente no fazer, e o fazer junto e isso "favorece e estabelece uma relação de correspondência" (INGOLD, 2013, p.107), tomando as coisas a partir de sua produção em diferentes âmbitos disciplinares. Através da prática e da experiência, somos capazes de falar do que sabemos; o que precisamos e porque dizer. Neste sentido, observamos que todos são capazes de fazer design, no entanto, para que o trabalho em conjunto seja produtivo e obtenha bons resultados é importante identificar quem o faz e quais suas contribuições nesse processo. Desse modo, deve-se reconhecer que as coisas fluem e que os objetos não são materiais, mas que vivem como materiais para além de produções imagéticas da consciência - a imaterialidade - através dos valores simbólicos e identitários que cada material/objeto carrega, como exemplo das sementes ornamentais encontradas na APA do Maracanã que contam sua história, tradições e folclores pelas mãos de seus artesãos.

Para Oliveira (2000), observar significa ver que o acontece no entorno, além de ouvir e sentir. Participar significa fazê-lo a partir de dentro da corrente de atividades através da qual a vida transcorre, concomitante e conjuntamente com as pessoas e coisas que capturam a atenção que se dispensa a elas (INGOLD, 2016). Enquanto uma maneira de trabalhar - ou talvez, uma expressão condensada do modo como todos trabalham -, a observação participante é um procedimento que toma amplitude ao longo da pesquisa.

O trabalho conjunto de processamento das sementes ornamentais realizado pelos designers e artesãs do Maracanã configura-se com um processo de correspondência, pois ambos os atores participantes trocam suas experiências sobre a melhor maneira de se trabalhar com o material - as sementes - e o que este material simboliza a cada um e o mais importante dedicam sua atenção a como esse fluxo transcorre.

\section{Pondo em prática: design e sustentabilidade através das sementes}

Ao longo dos anos a relação design e sustentabilidade tem sido fundamental na busca pela equidade nos modos de produção e consumo. Sampaio et al (2018, p. 24) orientam que cabe ao design o papel principal de idealizar produtos e serviços que utilizem os recursos de forma mais eficientes, além disso, novos sistemas de serviços que inspirem mudanças o comportamento das pessoas quanto ao consumo e atendam necessidades com menos impactos. Para alcançar este equilíbrio, o designer precisa vislumbrar oportunidades em todas as "dimensões da sustentabilidade" econômica, social, ambiental e cultural (SACHS, 2002; VEZZOLI et al, 2018), pois o design é um dos caminhos que possibilitam esta integração.

\subsection{Sementes que inspiram as mulheres do Maracanã}

Por meio da parceria com mulheres foi possível construir um percurso de atividades que permitisse o entendimento sobre suas experiências, anseios, perspectivas e sonhos na atividade 
artesanal com sementes. Num primeiro momento, através de seminários, palestras, rodas de conversa, oficinas e experimentos, propostos pelos designers e em um segundo momento acompanhando a rotina cotidiana destas mulheres, conseguiu-se formar um grupo com o intuito de desenvolver produtos a partir da valorização do saber popular, respeito ao meio ambiente, reconhecimento do território, possibilitando a estas mulheres oportunidade de renda e de autorreconhecimento - o grupo de artesãs Fruta Rara.

Num processo de construção coletiva por meio do codesign o nome do grupo foi gerado, enaltecendo o que de mais rico as artesãs tinham em mãos, a semente do fruto da juçara, até então a única espécie usada na produção das biojoias. A prática do codesign é uma forma de pesquisa em design que envolve os usuários no processo de criação. Lupton (2014), afirma que no processo de codesign há uma participação ativa de todos os envolvidos - stakeholders enfatizando suas experiências. Clay Spinuzzi (2005), por sua vez, ressalta que se trata de uma forma de entender o conhecimento do outro fazendo suas atividades cotidianas e como essas atividades podem ser moldadas de maneira proativa. Noronha (2012) fundamenta que nesse contexto há um deslocamento do design, do centro para o meio, ou seja, os designers devem apresentar uma postura de tradutores e mediadores efetivos e não reprodutores de linguagem, apresentando-se como parte do processo colocando-se no mesmo patamar do artesão e não acima dele. Durante a pesquisa, foi possível destacar melhorias e contribuições nas atividades com sementes dentro das quatro dimensões da sustentabilidade, tais como:

- Quanto ao aspecto econômico: a importância da atividade enquanto fonte de renda pela venda, aprimoramento e variedade dos produtos artesanais desenvolvidos pelas artesãs; Revelação custo versus benefício positiva para as artesãs, pois todo o processo da cadeia produtiva do artesanato é de baixo custo.

- Quanto ao aspecto social: as artesãs ganharam autonomia através da atividade artesanal e o reconhecimento do trabalho pelos outros habitantes da comunidade; autorreconhecimento, autoestima elevada, melhorias no convívio familiar, bem-estar; sensação de pertencimento ao seu território;

- Quanto ao aspecto ambiental: ações de conscientização sobre conservação e valorização dos recursos naturais da APA devido ao processo de degradação que vem sofrendo as áreas de floresta da localidade com o avanço das construções habitacionais no entorno; aprimoramento das técnicas de manejo e beneficiamento das sementes - uso de tingimento natural de modo que não danificar o solo, imunização com óleos naturais em vez de inseticidas, extração consciente dos frutos e sementes para possibilitar a recuperação das palmeiras outras espécies arbóreas.

- Quanto ao aspecto cultural: valorização das tradições, do saber popular, dos símbolos que representam o Maracanã expressas nas peças artesanais desenvolvidas.

Considerando estes apontamentos construídos durante a pesquisa, Rodrigues (2013), afirma que o designer comprometido com a sustentabilidade considera todo o ciclo de vida do produto, ou seja, a cadeia produtiva, desde a extração da matéria-prima até as etapas de produção e utilização. Manzini e Vezzoli (2008) concordam com esta prerrogativa explicando que a sustentabilidade deveria ser o meta-objetivo de todas as possíveis pesquisas em design. Thackara (2008) completa destacando que precisamos retomar a um padrão de vida em maior sintonia com os ritmos da biosfera, ou seja, deve-se priorizar a qualidade de vida para projetar de forma consciente. Essa discussão nos remete ao conceito de bem viver, cunhado por Alberto Acosta (2017), orientado para a melhoria da qualidade de vida dessas artesãs e de suas famílias através da atividade e para a construção de uma vida em pequena escala, sustentável e equilibrada na qual a atividade com sementes ornamentais pode oferecer, pois considera uma relação de produção autônoma, renovável e autossuficiente. 


\subsection{Sementes que se transformam: cadeia produtiva}

Figura 02: amostras de espécies de sementes da APA do Maracanã.

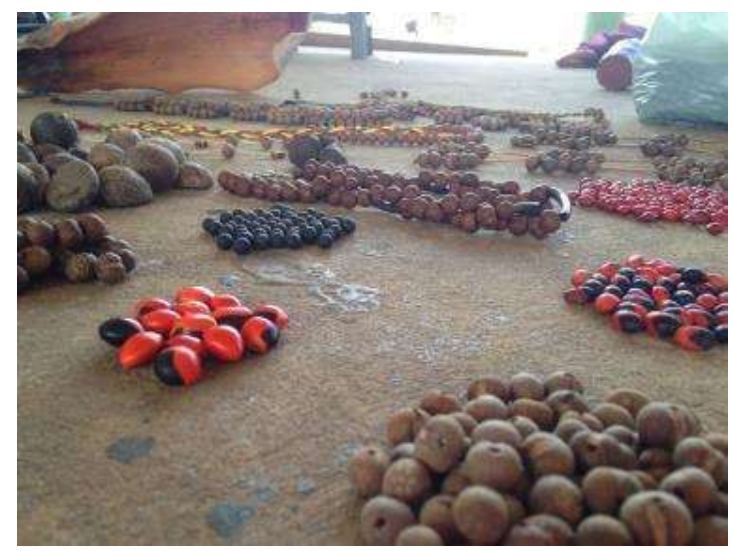

Fonte: Das autoras, (2018).

Krucken (2009) informa que para desenvolvermos uma visão sistêmica do processo de transformação e da agregação de valor econômico a recursos naturais é crucial compreender os sistemas de criação e de transmissão de valor (denominados cadeias, constelações e redes), diante dessa premissa buscou-se identificar elementos que pudessem permitir a elaboração do sistema para transformação das sementes nativas (Figuras 02 e 03). Neste sentido, após reconhecimento do ambiente da pesquisa (não em sua totalidade, mas um recorte) e das habilidades manuais das mulheres com o trabalho artesanal, observando e acompanhando sua rotina, pôde-se definir a cadeia produtiva do artesanato com sementes ornamentais a partir de alguns exemplares enfatizando desde o momento da coleta da semente em sítios e brejos até o momento de exposição e venda dos artefatos resultantes, todo o percurso foi realizado junto às artesãs.

Figura 03: Estrutura simplificada da cadeia produtiva de sementes ornamentais do Maracanã.

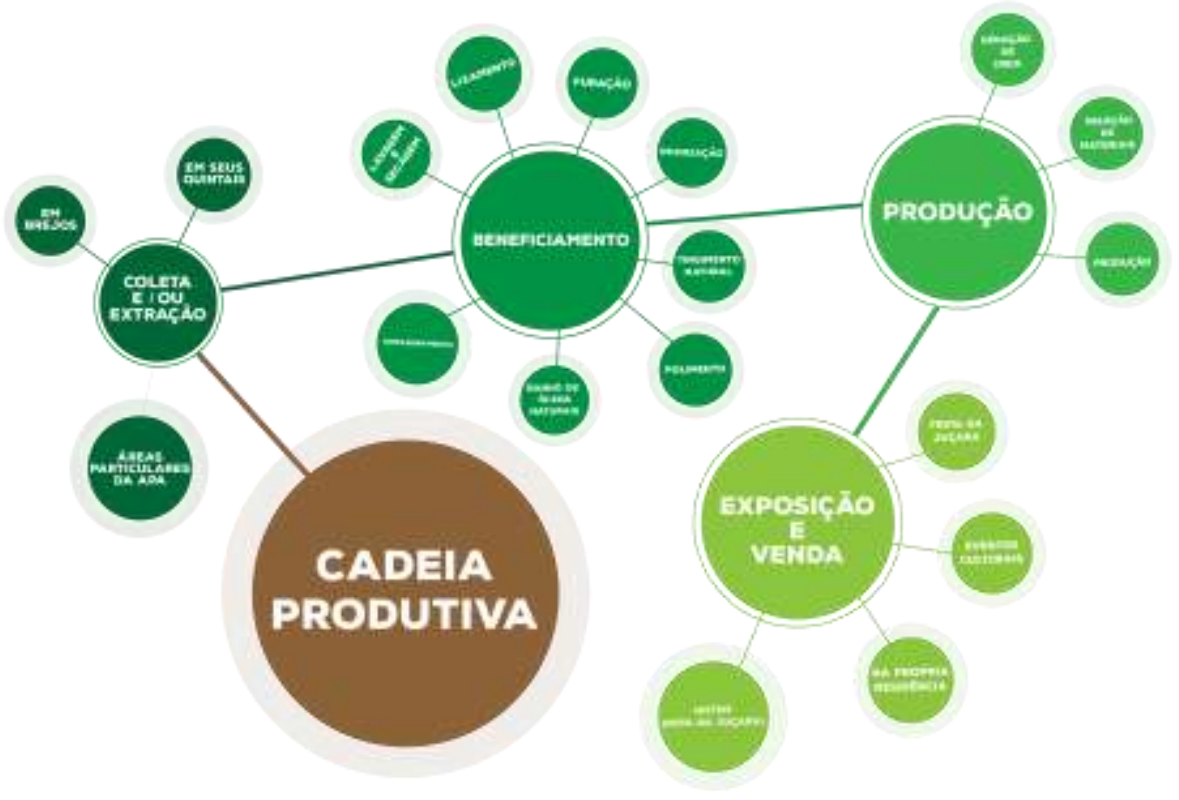

Fonte: Das autoras, (2019).

No primeiro momento, as sementes ornamentais antes de se tornarem peças artesanais como biojoias - precisam ser submetidas a um tratamento/processo para adquirir resistência, cor 
e aparência ideal ao fim proposto. Logo, trabalhamos com a atividade de beneficiamento, responsável pela preparação e melhoramento das sementes. Se apresenta em onze sub-etapas: coleta, lavagem, secagem, lixamento, seleção, furação, imunização, tingimento natural (no caso da semente da juçara), polimento, banho com óleos naturais para a conservação e brilho e por último, a armazenagem. É importante ressaltar que nem todas as espécies de sementes precisam passar por todo o processo como exemplo as etapas de lixamento e tingimento, pois tais espécies já conferem em sua estrutura, textura e cores ideais.

Figura 04: Etapas de beneficiamento de sementes

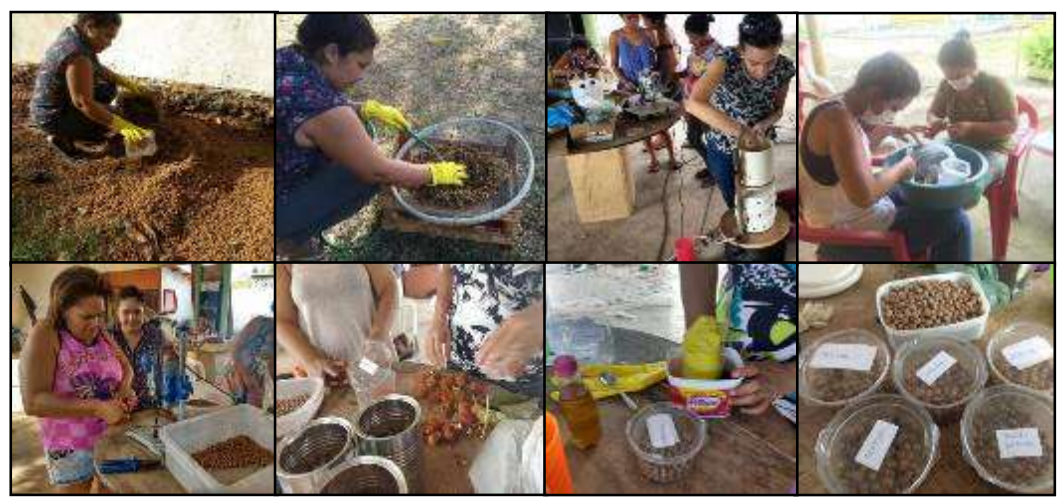

Fonte: Das autoras, (2017).

O segundo momento é dedicado à elaboração das peças, o mais aguardado pelas artesãs, quando, elas afloram a criatividade. A partir da geração de ideias, informações sobre conceito da coleção e recursos materiais são levantadas. Recursos didáticos propostos pelo designer como observação e reconhecimento de elementos característicos do território - fauna, flora, cultura, economia através de imagens; apreciação do som ambiente e canções que enaltecem o Maracanã; Produção de Moodboards (ferramenta de criatividade) com elementos que possam representar o ambiente (recorte de revistas, folhas, desenhos, palavras), ajudam a ampliar a percepção e o imaginário das artesãs no processo criativo. Algumas artesãs rabiscam pequenas ideias no papel enquanto outras com menos habilidade no desenho, preferem desenvolver protótipos diretamente nos materiais disponíveis, cada uma responde de uma forma, a mente flui, logo, o conceito para coleção e as primeiras ideias começam a surgir, mas leva-se um tempo para amadurecê-las. Em outro momento, tratamos da seleção mais detalhada dos materiais e das técnicas de acabamento a serem empregadas, além da definição das medidas de cada modelo, as informações são todas catalogadas pelas artesãs, como um inventário. Por fim desta etapa, iniciase a produção das peças que quando prontas são devidamente embaladas, etiquetadas, e seguem para pontos de exposição e venda, em eventos dentro da própria comunidade como na tradicional Festa da Juçara, para qual a produção é intensificada.

Figura 05: Geração de ideias e produção das peças

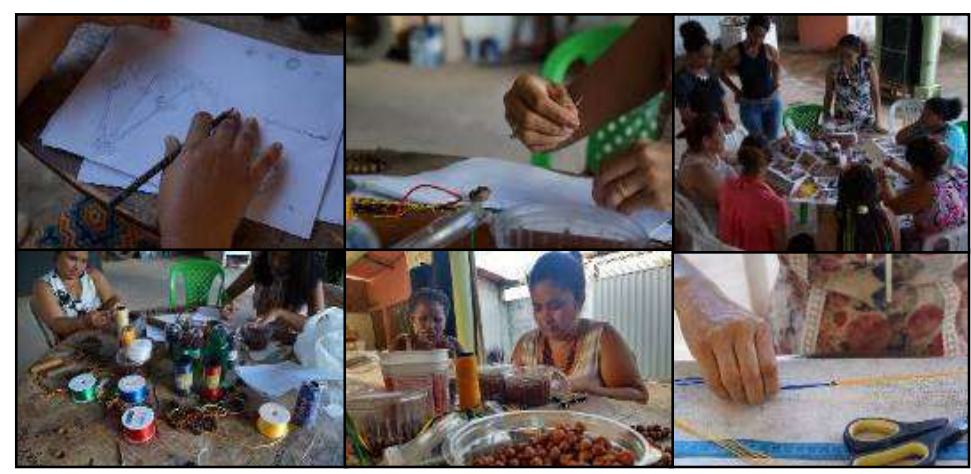




\subsection{Frutos colhidos ao longo do caminho}

Desde 2017, o jovem grupo composto por artesãs experientes têm se fortalecido gradativamente, esse fortalecimento ganha maior ênfase durante a exposição e venda das peças, geralmente realizadas na Festa da Juçara na própria comunidade, as artesãs relatam que sentem imenso prazer e satisfação em repassar ao visitante sobre todas as etapas do processo de beneficiamento das sementes e as histórias por trás de cada modelo das coleções desenvolvidas, suas experiências de vida e o contexto sobre o território. De imediato, esse contato gera a empatia do cliente potencial pelo grupo e o encantamento pelo produto proporcionando um momento de imenso valor ao trabalho dessas mulheres.

Figura 06: Exposição e venda Festa da Juçara

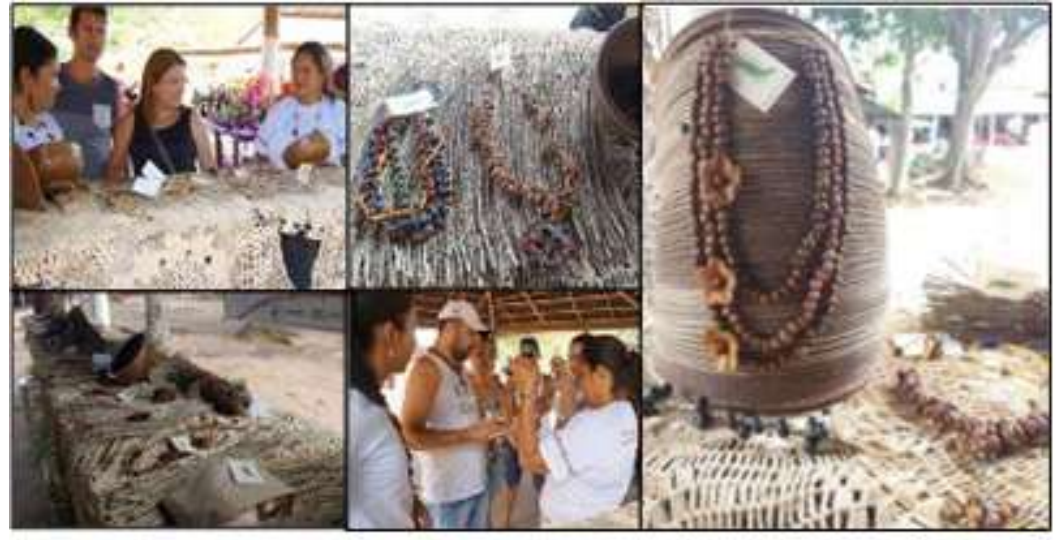

Fonte: Das autoras, (2017).

As peças também são vendidas em eventos culturais e hotéis de São Luís, localizados na Avenida Litorânea, orla marítima da cidade, grande extensão de praias, área turística, como forma de enaltecer o artesanato local. Esses hotéis são parceiros da Rota da Juçara ${ }^{6}$ importante expedição em trilha ecológica na mata fechada com $1.200 \mathrm{~km}$ de extensão na APA do Maracanã, onde os nativos da região trabalham como guias e trazem informações sobre a fauna e flora da reserva ambiental durante todo o percurso com destaque para as palmeiras de juçara (TAGUATUR, 2018).

A APA do Maracanã foi criada por meio do Decreto 12.103 de 01 de dezembro de 1991, com área aproximada a 1831 ha., movido pela preocupação em proteger e conservar as espécies naturais da região, principalmente os juçarais, da ação do Distrito Industrial e da ocupação desordenada (MARANHÃO, 1991), possui uma riqueza natural incontestável, apresentando nuances de biomas em sua vegetação, como matas de galeria margeadas por juçarais e buritizais caracterizando a parte alagada, babaçuais, cupuaçu e abricó entre outras espécies amazônicas, localizadas em sítios, além de espécies normalmente vistas no cerrado com os ipês-amarelos, paumarfim e bacuri. A Rota da Juçara ajuda a fomentar o turismo ecológico na região e no Estado (FRAZÃO, 2017).

\section{Considerações Finais}

A atividade artesanal se apresenta de modo bastante dinâmico, pois está inserida na economia local e nas relações dos artesãos com sua história ao longo do processo produtivo. No entanto é

\footnotetext{
${ }^{6}$ Fonte: TAGUATUR online.
} 
importante ressaltar que a atividade artesanal não se restringe apenas à tradição ou à distribuição comercial, pois possui caráter diverso e heterogêneo, para além do aspecto simbólico e capitalista, mas também ao mundo das relações socioambientais, de produção e cultura, pautadas a valores essenciais como: identidade, responsabilidade social e equilíbrio sustentável.

No decorrer desta pesquisa, ainda em andamento, podemos considerar preliminarmente que o design precisa vislumbrar a possibilidade de desenvolver produtos oriundos de técnicas tradicionais desenvolvidas por comunidades criativas como o Maracanã, como forma de entender a fundo cada processo, de acordo com a necessidade demandada. Assim como considerar no percurso projetual a equidade entre as dimensões da sustentabilidade, os aspectos tangíveis, e intangíveis dos materiais, o fazer coletivo, a empatia e os sentidos.

A relação design-ambiente resulta em produtos com baixo impacto ambiental, valor agregado e outros resultados satisfatórios, pois o designer concentra-se em estratégias de projeto que viabilizem toda a cadeia produtiva, inclusive com a participação da comunidade a partir do fazer, que é a vivência e do saber que são as experiências de cada um, tanto o que surge do empirismo quanto o aprendido nas instituições acadêmicas.

Com a abordagem do DA por meio das práticas de correspondência que surgem do fazer junto, pudemos perceber quanto o papel do design na produção do artesanato local tem sido mediativa e propositiva, pois dela identificam-se as reais necessidades da comunidade. A correspondência surge por meio da convivência, da atenção dada a atividade do outro, no transcorrer do fluxo da vida coletivo, logo, traz maior abertura para o diálogo entre os atores presentes na cadeia de valor, ampliando o imaginário na busca de soluções que atinjam a equidade. Trazendo para o contexto do Maracanã, tais soluções possibilitam melhorar a qualidade de vida destas pessoas, o resgate dos valores individuais e coletivos, autonomia financeira, o reconhecimento de sua identidade, a preservação e conservação do ambiente, a valorização do território, através da ação do design em correspondência com o saber-fazer popular.

\section{Referências}

ACOSTA, Alberto. O bem viver: uma oportunidade para imaginar outros mundos: 2. ed. São Paulo: Autonomia Literária: Elefante., 2017. Tradução de: Tadeu Breda.

BINDER, Thomas et al. Design Things. Cambridge, Mass., United States: Mit Press, 2011. 256 p.

BRANDT, Eva et al. Formating Design Dialogues - Games and Participation. In: BINDER, T; BRANDT, E; GREGORY, J. (guest editors). CoDesign - International Journal of CoCreation in Design and the Arts, Volume 4, Number 1, pp. 51-64. Taylor \& Francis. March, 2008.

CARDOSO, Rafael. Uma introdução à história do design. São Paulo: Edgard Blücher, 2008.

CORREA, Gisele Reis. Design e Artesanato: um estudo de caso sobre a semente de juçara em São Luís do Maranhão. 2010. 149 f. Dissertação (Mestrado) - Curso de Mestrado em Design, Universidade Federal de Pernambuco UFPE, Recife, 2010.

FRAZÃO, Ana Claudia dos Santos. Diversidade Florística da Área de Proteção Ambiental do Maracanã em São Luís Ma: Implicações para o manejo e conservação.. 2017. 60 f. Monografia Curso de Curso de Ciências Biológicas, UFMA Campus Chapadinha, 2017.

HALSE, Joachim. Ethnographies of the possible. In: GUNN, Wendy; OTTO, Ton; SMITH, Rachel Charlotte (eds). Design Anthropology: theory and practice. London, New York: Bloomsbury, 2013. HALSE, J.; BRANDT, E.; CLARK, B.; BINDER, T. (Eds.). Rehearsing the future. Copenhagen: The Danish Design School Press, 2010. 211 p.

HOCKEY, Jenny; FORSEY, Martin. Ethnography is not participant observation: reflections on the interview as participatory qualitative research. In the interview: an ethnographic approach, edited by Jonathan Skinner. New York: Berg, 2012. p. 69-87. 
INGOLD, Tim. Chega de etnografia! A educação da atenção como propósito da antropologia. Tradução: Revista Educação. Porto Alegre, v. 39, n. 3, p. 404-411, set.-dez. 2016.

Making: Anthropology, Archaeology, Art and Architecture. Londres/Nova York: Routledge, 2013, 176p.

. Trazendo as coisas de volta à vida: Emaranhados criativos num mundo de materiais. Horizontes Antropológicos, Porto Alegre, Ano 18, n. 37, p. 25-44, jan/jun. 2012.

KRUCKEN, Lia. Design e território: Valorização de identidade e produtos locais. Ed. Studio Nobel. SEBRAE. 2009. São Paulo - SP.

LUPTON, Ellen. Intuição, ação, criação: Graphic Design Thinking. 2a Ed. São Paulo: G Gili Ltda, 2014.

MANZINI, Ezio. VEZZOLI, Carlo. O desenvolvimento de produtos sustentáveis. São Paulo: Editora Edusp, 2008.

MARANHÃO. Secretaria do Meio Ambiente e Turismo. Decreto 12.103, de 1 de dezembro de 1991. Cria, no Estado do Maranhão, a Área de Proteção Ambiental da Região do Maracanã, com limites que especifica e dá outras providências, Diário Oficial [do] Estado do Maranhão, São Luís. 1991.

NORONHA, Raquel. The collaborative turn: challenges and limits on the construction of the common plan and on autonomía in design. Strategic Design Research Journal, 11(2): 125-135, May-August, 2018.

. Do centro ao meio: um novo lugar para o designer. São Luís: Anais do 10 P\&D, 2012.

OLIVEIRA, Roberto Cardoso de. Identidade, Etnia e Estrutura Social. Livraria Pioneira Editora. São Paulo: 1976.

OTTO, Tom; SMITH, Rachel Charlotte. Design anthropology: A distinct style of knowing. In: GUNN, Wendy; OTTO, Ton; SMITH, Rachel Charlotte (eds). Design Anthropology: theory and practice. London, New York: Bloomsbury, 2013.

EHN, Pelle. Learning in participatory design as I found it. In: DISALVO, Betsy et al. Participatory Design for Learning Perspectives from Practice and Research ROUTLEDGE, 2015.

PORTELA, Raiama Lima. Correspondências por meio de ferramentas de design: artesanato e empoderamento (aprisionamento?). 2018. 130 f. Dissertação (Mestrado) - Universidade Federal do Maranhão - UFMA, São Luís, 2018.

PROGRAMA DO ARTESANATO BRASILEIRO. Disponível em <http://pab. desenvolvimento.gov.br/tempplaste.asp?id=maranhão>. Acesso em: 29 out.2017.

REDE DE SEMENTES DA AMAZÔNIA. Disponível em http://www.rsa.ufam.edu.br:8080/sementes/anal-semente/anal-semente.jsp - 10k. Acesso em: 04 nov.2017

SAMPAIO, Claudio P. (Org.). Design para a sustentabilidade: Dimensão Ambiental. Curitiba, PR: Insight, 2018.

SANDERS, Elizabeth B.N. From User-Centered to Participatory Design Approaches. In Design and the Social Sciences. J.Frascara (Ed.), Taylor \& Francis Books Limited, 2002.

SARNEY Ivan. A bela Festa da Juçara no Maracanã. 2011. Disponível em: http://www.academiamaranhense.org.br/blog/a-bela-festa-da-jucara-no-maracana/

SPINUZZI, Clay. The Methodology of Participatory Design. APPLIED RESEARCH. Volume 52, Number 2, May 2005. Tech 2005.

TAGUATUR, turismo e eventos. Rota da Juçara. 2018. Disponível em: https://www.taguaturonline.com.br/produto/rota-da-jucara/Acesso em: 12 de setembro de 2018.

THACKARA, John. Plano B.: O design e as alternativas viáveis em um mundo complexo. Trad. Cristina Yamagami. São Paulo: Saraiva. 2008.

VEZZOLI, Carlo. (Org.) Sistema Produto+Serviço Sustentável: Fundamentos. Curitiba, PR: Insight, 2018. 